\title{
ARBITRAJE EUROPEO: UNA CRÍTICA A LA SENTENCIA DEL TRIBUNAL CONSTITUCIONAL 65/2021, DE 15 DE MARZO
}

\author{
EUROPEAN ARBITRATION: A CRITICAL REVIEW OF THE \\ JUDGMENT OF THE CONSTITUTIONAL COURT 65/2021, \\ OF MARCH 15
}

\author{
Miguel Gómez Jene \\ Catedrático de Derecho Internacional Privado \\ UNED \\ ORCID ID: 0000-0002-4916-5119
}

Recibido: 11.07.2021 / Aceptado: 27.07.2021

DOI: https://doi.org/10.20318/cdt.2021.6290

\begin{abstract}
Resumen: La sentencia del TC objeto de comentario otorga el amparo y anula una sentencia del TSJ de Madrid en virtud de la cual se anulaba un laudo arbitral. El laudo, pese a ser dictado en equidad, trae causa de un arbitraje europeo, en la medida en que al fondo de la controversia le era aplicable Derecho imperativo de la UE. Esta circunstancia es crucial, pues en virtud de las sentencias Eco Swiss y Achmea, del TJUE, el control que debe ejercer el tribunal que conoce de la anulación del laudo es particularmente intenso: en palabras del TJUE, el juez debe "examinar" la aplicación del Derecho imperativo de la UE. Lejos de tener en cuenta esta jurisprudencia -aplicable al caso- el TC se desmarca con una interpretación difícilmente conciliable con la jurisprudencia del TJUE. Desde esta perspectiva, cabe preguntarse si el mismo TC ha vulnerado el derecho del justiciable a un proceso con todas las garantías (art. 24.2 CE), en la medida en que no ha resuelto conforme al sistema de fuentes establecido.

Palabras clave: Arbitraje europeo. Derecho imperativo de la UE. Motivación. Laudo en equidad. Orden público.

Abstract: The judgment of the Constitutional Court (CC) granted constitutional protection and annulled a judgment of the High Court of Madrid by virtue of which an arbitral award was annulled. The award, although rendered in equity, arose from a European arbitration, insofar as mandatory EU law was the applicable law to the merits. This circumstance is crucial, since under the CJEU's Eco Swiss and Achmea judgments, the scrutiny to be exercised by the court hearing the annulment of the award is particularly intense: in the words of the CJEU, the judge must "examine" the application of mandatory EU law. Far from taking into account this case law - applicable to the case - the CC dissociates itself with an interpretation that is difficult to reconcile with the case law of the CJEU. From this perspective, it is worth asking whether the Constitutional Court itself has violated the right of the defendant to due process (art. 24.2 EC), insofar as it has not ruled in accordance with the established system of sources.

Keywords: European arbitration. Mandatory EU law. Statement of reasons. Award in equity. Public policy.

Sumario: I. Introducción. II. Arbitraje europeo: delimitación. III: Laudo en equidad. IV. Aplicación de la cláusula de orden público: la motivación de los laudos arbitrales sí tiene incidencia en el orden público. V. La cuestión prejudicial. VI. Anulación parcial por aplicación de la cláusula de orden público. VII. A modo de conclusión.
\end{abstract}




\section{Introducción}

1. Pasado un plazo prudencial desde que el Tribunal Constitucional (TC) dictara su particular saga de sentencias vinculadas a la acción anulación en materia de arbitraje ${ }^{1}$ y pasado también un plazo prudencial para la necesaria divulgación de las mismas ${ }^{2}$, conviene centrarse ahora en aquella sentencia que, a mi juicio, requiere mayor atención: la STC 65/2021, de 15 de marzo. La sentencia en cuestión otorga el amparo al demandante, que solicitaba la anulación de una sentencia del TSJ de Madrid que, a su vez, anulaba un laudo arbitral dictado en equidad, pero que resolvió la controversia en aplicación de normas imperativas del Derecho de la Unión Europea (UE). En efecto, el arbitraje que está en el origen de este asunto era un arbitraje que bien podría calificarse -en términos coloquiales- como un "arbitraje SWAP": un arbitraje que resuelve una controversia a la que, ineludiblemente, le es de aplicación las Directivas MIFID ${ }^{3}$. De este dato fundamental deriva el interés de la sentencia seleccionada y conviene, por tanto, insistir en ello: el arbitraje del que trae causa esta sentencia es un arbitraje europeo que, por la materia a resolver, exigía la aplicación de normas imperativas del Derecho de la Unión (transpuestas al ordenamiento interno).

2. Tan determinante circunstancia pasa, sin embargo, totalmente desapercibida para el TC y, en consecuencia, dicta un fallo que se caracteriza por adoptar un enfoque extraordinariamente restringido sobre la cuestión relativa a la motivación del laudo. De hecho, al ignorar por completo la decisiva relevancia de la jurisprudencia del TJUE sobre el control del laudo que resuelve en aplicación de normas imperativas del Derecho de la Unión, el TC realiza una serie de afirmaciones tan tajantes como desafortunadas. No repara el TC en que control del laudo y motivación del mismo no son cuestiones o compartimentos estancos; son, antes al contrario, cuestiones que, en un supuesto como el de autos, van de la mano: como con criterio ha establecido el TJUE en su sentencia Achmea, en expresa referencia al arbitraje comercial, el control en sede de anulación exige que las normas imperativas del Derecho de la Unión "puedan ser examinadas"4. Repárese bien en el término escogido por el Tribunal de Justicia: "examinadas"; término que, en buena lógica, demanda una intensidad de revisión que alcance a la motivación.

3. Así las cosas, en las siguientes líneas me limitaré a demostrar cómo la jurisprudencia del TJUE ha impuesto, por un lado, un canon de control del laudo particularmente intenso para supuestos concretos de aplicación de normas imperativas y, por otro, la obligación de invocar la cláusula de orden público en aquellos supuestos en los que no se supere dicho control. De lo anterior se deducirá que, en el contexto del arbitraje europeo, no caben afirmaciones -por erróneas- como las que hace la sentencia objeto de comentario: "la motivación de los laudos arbitrales carece de incidencia en el orden público". Con carácter previo pondré de relieve la importancia capital de la dimensión europea del supuesto y, desde esta perspectiva, definiré lo que entiendo que debe calificarse como arbitraje europeo (cómo se identifica) y qué consecuencias se derivan de tal calificación tanto para el justiciable como para el órgano judicial del Estado miembro que controla el laudo.

4. No entraré, por tanto, en el análisis del laudo -cubierto bajo el manto de la equidad-, por más que estime que la jurisprudencia del TJUE no es compatible con ciertas afirmaciones que parecen insertas en el mismo y transcribe el TC en su fallo: "el laudo denegó la indemnización de daños y perjuicios al no haber ocasionado el contrato SWAP perjuicio alguno, pues el contrato cumplió su función y la demandante incurrió en deslealtad por retraso en la reclamación". A mi juicio, no puede arrebatársele al justiciable, bajo el argumento hueco de la deslealtad, el momento en que éste debe presentar su de-

\footnotetext{
${ }^{1}$ STC 46/2020, de 15 de junio, ECLI:ES:TC:2020:46; STC 17/2021, de 15 de febrero, ECLI:ES:TC:2021:17; STC 55/2021, de 15 de marzo, ECLI:ES:TC:2021:55; y, la sentencia objeto de este comentario, STC 65/2021, de 15 de marzo, ECLI:ES:TC:2021:65.

2 Vid. La Ley Mediación y Arbitraje, Abril 2021, Núm. 6, dedicado íntegramente a comentar estas sentencias.

3 Tanto las Directivas como Reglamento aplicables en este contexto, así como el derecho interno en el que aquellas normas se desarrollan están convenientemente citadas en el relevante voto particular de la sentencia que el TSJ de Madrid ha dictado en este asunto tras la sentencia del TC: STSJ de Madrid, 21 abril 2021, ECLI:ES:TSJM:2021:4401.

4 STJUE 6 marzo 2018, C-284/16, Achmea, ECLI:EU:C:2018:158, § 54.
} 
manda o solicitud de arbitraje. En el contexto del derecho bancario, la jurisprudencia del TJUE evoluciona de forma lenta pero rigurosa y será por tanto, a la luz de los criterios que esta jurisprudencia vaya asentando, cuándo y cómo se determine la forma y el momento en que la tutela judicial deba o pueda ser ejercitada. Nada hay de desleal en quien espera, por ejemplo, a un concreto pronunciamiento del TJUE o del TS para ejercer su tutela.

\section{Arbitraje europeo: delimitación}

5. La jurisprudencia del TJUE afecta con particular intensidad al arbitraje comercial internacional; y lo hace desde muchas y relevantes perspectivas: desde la eficacia de las mismas anti-suit injunction $^{5}$, hasta la posibilidad de adoptar y reconocer medidas cautelares en apoyo de un arbitraje ${ }^{6}$, pasando por el control del laudo que aplica Derecho imperativo europeo al fondo de la cuestión ${ }^{7}$. Tan es así, que la jurisprudencia del TJUE alcanza y afecta directamente a la interpretación que los tribunales de los Estados miembros deben hacer del Convenio de Nueva York de 1958 (CNY): recuérdese, en efecto, que en su célebre sentencia $E c o$ Swiss ${ }^{8}$, el TJUE impuso -que no sugirió- una interpretación concreta y determinada del artículo V.2.b/ CNY (orden público) en aquellos supuestos en los que el laudo resolviese la controversia en aplicación de Derecho imperativo de la UE. En el epígrafe correspondiente analizaré más detenidamente el alcance de esta jurisprudencia y su repercusión al supuesto de autos.

6. Siendo por tanto incuestionable que la jurisprudencia del TJUE afecta directamente al arbitraje internacional desde muy distintas perspectivas, cabe preguntarse entonces por los criterios que un arbitraje debe reunir para considerarse europeo. De tal forma que, de ser calificado como tal, el arbitraje quedaría automáticamente afectado por la jurisprudencia del TJUE. Pues bien, desde esta perspectiva, entiendo que puede calificarse como arbitraje europeo un arbitraje cuya sede se localice en un Estado miembro y, cumulativamente, aplique Derecho de la UE (en cualquiera de sus manifestaciones) al fondo de la controversia. Con independencia absoluta del lugar de residencia de las partes; que podrá ser o no en un mismo Estado miembro, en distintos Estados miembros de la UE, o en el mismo o en distintos terceros Estados. Es decir, la dimensión europea del arbitraje viene dada por circunstancias muy particulares -ajenas a un criterio espacial- como son, cumulativamente, el Derecho europeo aplicable al fondo, por un lado, y por la competencia de un tribunal de un Estado miembro para controlar el laudo, por otro'. Si cumulativamente se dan ambas circunstancias, los órganos jurisdiccionales deberán ejercer un control sobre el laudo acorde con el mandato diseñado por el TJUE en su jurisprudencia, pues aunque para el TC haya pasado desapercibida, la jurisprudencia del TJUE impone una particular forma de analizar el laudo cuando el mismo resuelva una controversia en aplicación del Derecho de la UE.

7. La dimensión europea alcanza tal magnitud y relevancia que, de darse, la aplicación de otras normas convencionales al supuesto puede quedar totalmente desplazada. Es decir, ante un arbitraje europeo, la posible aplicación del artículo VIII del Convenio de Ginebra de 1961 sobre arbitraje comercial internacional (CG) -que, en esencia, permite la no motivación del laudo- queda totalmente desplazada si su aplicación supone tanto como contravenir la jurisprudencia del TJUE. Y ello es así, otra vez, porque el mismo TJUE se ha preocupado mucho de señalar que el Derecho convencional en vigor entre los Estados miembros solo puede ser de aplicación cuando su aplicación al supuesto no desvirtúe la eficacia del Derecho europeo ${ }^{10}$. En consecuencia, si el arbitraje cuyo laudo es sometido a anulación es calificable

\footnotetext{
${ }^{5}$ STJUE 10 febrero 2009, C-185/07, Allianz (también conocida como West Tankers), ECLI:EU:C:2009:69.

6 STJUE 17 noviembre 1998, C-391/95, Van Uden, ECLI:EU:C:1998:543.

7 STJCE 1 junio 1999, C-126/97, Eco Swiss, ECLI:EU:C:1999:97; y sentencia Achmea citada en nota a pie núm. 4.

8 Vid. nota anterior.

${ }^{9}$ La relevancia que en este contexto de calificación tiene el Derecho europeo aplicable al fondo viene establecida de forma expresa en la sentencia Achmea (nota a pie núm. 4).

10 STJUE 4 mayo 2010, C-533/08, TNT, ECLI:ES:C:2010:243; STJUE 19 diciembre 2013, C-452/12, Nipponkoa, ECLI:ES:C:2013:858; y, STJUE 4 septiembre 2014, C-157/13, Nickel, ECLI:ES:C:2014:2145.
} 
como europeo, no es posible invocar el artículo VIII CG para justificar la falta de motivación del mismo en supuestos en los que el laudo sí deba estar motivado (por aplicación de normas imperativas del Derecho de la UE). Este precepto convencional cede ante la jurisprudencia del TJUE que exige, para determinados supuestos, cierto nivel de revisión.

8. Asentadas por tanto las bases que tuvo que tener en cuenta el TC -y que no tuvo-, analizaremos la jurisprudencia del TJUE que, sin duda, hubiera obligado al órgano constitucional español a dar otra respuesta al supuesto; no sin antes demostrar que el carácter en equidad del laudo en nada condiciona o desvirtúa la necesaria consideración de la jurisprudencia del TJUE al supuesto de autos.

\section{Laudo en equidad}

9. Es sabido, y no requiere mayores explicaciones, que bajo el manto de la equidad no puede desdibujarse la aplicación del Derecho imperativo al fondo del asunto. Ese es, precisamente, el límite de la equidad ${ }^{11}$. En consecuencia, en el asunto de autos, el hecho de que el arbitraje fuera de equidad, es cuestión irrelevante: en la medida en que eran de aplicación las Directivas MIFID (normas imperativas de la Unión), el juez encargado del control del laudo debió, y así lo hizo en el primer fallo, "examinar" (en terminología intencionada del TJUE) la aplicación de las normas que las transponen al supuesto. El reproche que hace por tanto el TC a la intensidad de control es muy desafortunado: el juez de anulación debe examinar el laudo que resuelve en aplicación del Derecho imperativo de la UE, porque así se lo impone el TJUE. El hecho de que el arbitraje fuera de equidad no desvirtúa en modo alguno tal mandato.

10. A partir de lo anterior, se entenderá también que la siguiente afirmación del TC respecto del arbitraje de equidad, no puede extenderse a supuestos de aplicación de normas imperativas: "El canon de motivación, en este caso, es más tenue, si bien es imprescindible que se plasmen en el laudo los fundamentos -no necesariamente jurídicos- que permitan conocer cuáles son las razones, incluso sucintamente expuestas, por las que el árbitro se ha inclinado por una de las posiciones opuestas de los litigantes"”2.

\section{Aplicación de la cláusula de orden público: la motivación de los laudos arbitrales sí tiene inci- dencia en el orden público}

11. Hay ciertas afirmaciones en las recientes sentencias del TC en materia de arbitraje que deben acogerse con mucha cautela, pues su alcance puede verse necesariamente restringido según concurran o no determinadas circunstancias en el caso ${ }^{13}$. La circunstancia más relevante -y que es la que ahora importa- es la relativa a la aplicación de normas imperativas del Derecho de la Unión al fondo de la controversia. Tomando en cuenta esta circunstancia, la siguiente manifestación del TC -anterior a la sentencia objeto de comentario- tampoco puede aceptarse en toda su extensión: "habrá de recordarse que la anulación solo puede referirse a errores in procedendo, y no puede conducir a revisar la aplicación del derecho sustantivo por los árbitros, es decir, que las resoluciones arbitrales sólo son susceptibles de anularse en función de la inobservancia de las garantías de la instancia arbitral”"14.

12. Quizá para salvar la rotundidad del párrafo transcrito deba hacerse una interpretación muy amplia de lo que son errores in procedendo; de tal forma que este concepto abarque ciertos supuestos que,

${ }^{11}$ Expresamente en este sentido, Auto AP de Barcelona, 28 septiembre 2010, ECLI:ES:APB:2010:5651A. Vid. también en este sentido, M. Gómez Jene, Arbitraje comercial internacional, Madrid, Civitas, 2018, pp. 331-333; C. Esplugues Mota, “Artículo 34", en: S. Barona Vilar (Coor.), Comentarios a la Ley de Arbitraje, 2a Ed., Madrid, Civitas, 2011, p. 1372.

${ }_{12}$ STC 17/2021, de 15 de febrero ECLI:ES:TC:2021:17. Anteriormente, en el mismo sentido, STSJ del País Vasco, 11 diciembre 2019, ECLI.ES:TSJPV:2019:2423.

$13 \mathrm{Vid}$. las sentencias citadas en la nota 1.

${ }^{14}$ STC 17/2021 de 15 de febrero. ECLI:ES:TC:2021:17. 
en puridad, constituyen errores in iudicando. Este argumento podría incluso sustentarse en la definición tan amplia que el mismo TC ha hecho de la expresión "errores in procedendo"; contexto en el que sí aprecia el posible juego de la cláusula de orden público. El orden público en su vertiente procesal -viene a decir el TC- "sólo puede tener por objeto el análisis de los posibles errores procesales en que haya podido incurrir el proceso arbitral, referidos al cumplimiento de las garantías fundamentales, como lo son, por ejemplo, el derecho de defensa, igualdad, bilateralidad, contradicción y prueba, o cuando el laudo carezca de motivación, sea incongruente, infrinja normas legales imperativas o vulnere la intangibilidad de una resolución anterior" ${ }^{\prime 15}$. Es más, si bien se lee el párrafo transcrito, se aprecia una importante contradicción con la desafortunada expresión: "la motivación de los laudos arbitrales carece de incidencia en el orden público". En efecto, resulta que la motivación carece de incidencia en el orden público pero, sin embargo, la motivación está incluida en la definición amplia de errores in procedendo que, en su caso, sí permite activar la cláusula de orden público. Alimenta la confusión el siguiente párrafo, que ve similitudes entre la motivación de la sentencia y la motivación del laudo, pero que parece negar la aplicación del orden público para anular el laudo irrazonable: "no cabe duda de que la operación de enjuiciamiento de ambos tipos de resoluciones debe valerse de parecidos criterios, de modo que se puede afirmar que sólo a aquel laudo que sea irrazonable, arbitrario o haya incurrido en error patente podrá imputársele un defecto de motivación vulnerador del art. 37.4 LA (y reiteramos, no del art. 24.1 CE) ${ }^{16}$.

13. En cualquier caso -y aun a riesgo de ser reiterativos-, dice el TC en la sentencia objeto de comentario que "la motivación de los laudos arbitrales carece de incidencia en el orden público". Afirmación tajante y categórica que, por un lado y tal y como hemos demostrado en el párrafo anterior, contradice su misma jurisprudencia, y que, por otro, no puede aceptarse en el contexto de un arbitraje europeo como el que subyace en autos. De hecho, si llevamos tal afirmación al extremo -y a los meros efectos ilustrativos-, habremos de convenir que motivaciones del tenor "porque este árbitro estima que no son de aplicación normas imperativas del Derecho de la UE al supuesto" difícilmente podrán cuestionarse en sede de anulación: ¿qué motivo de anulación puede esgrimirse para anular un laudo que motiva de tal manera? Particularmente, no veo encaje posible ni el artículo 41.1.a/ (validez del convenio arbitral); ni el artículo 41.1.b/ (derechos de defensa); ni el artículo 41.1.c/ (incongruencia ultra petita, extra petita y citra petita); ni el artículo 41.1.d/ (irregularidades procedimientales); ni, por supuesto, en el artículo 41.1.e/ (arbitrabilidad de la materia) ${ }^{17}$. Es decir, a falta de mejor encaje u motivo ad hoc de anulación, estimo que la motivación del laudo que resuelve por aplicación de Derecho imperativo de la UE debe controlarse por el cauce de la cláusula de orden público. De nuevo, la jurisprudencia del TJUE soporta firmemente esta interpretación (infra 15).

14. Tomando en consideración los párrafos transcritos de la jurisprudencia del TC, paso ya a transcribir y comentar los párrafos de las sentencias Eco Swiss y Achmea que, a mi juicio, entran en contradicción con la sentencia del TC que comentamos. Tales párrafos marcan la senda que deben seguir los tribunales de los Estados miembros, como mínimo, en aquellos supuestos en los que o bien el Derecho de la Unión -Reglamentos- o bien el Derecho derivado de la Unión sea de aplicación al supuesto. Como se constatará, el TJUE defiende en sede de anulación una limitada revisión de los errores in iudicando del árbitro (algo que el TC, insisto en ello, parece impedir).

15. El punto de partida que ha planteado la sentencia Achmea en el contexto de una acción de anulación de un laudo arbitral que ha resuelto en aplicación de Derecho de un Estado miembro (en el caso, Derecho derivado de la UE) es, a mi juicio, más que explícito: “incumbe a los órganos jurisdiccio-

\footnotetext{
15 STC 17/2021 de 15 de febrero. ECLI:ES:TC:2021:17. Este párrafo se recoge en términos prácticamente idénticos en la sentencia objeto de comentario.

16 STC 17/2021 de 15 de febrero, ECLI:ES:TC:2021:17.

17 Vid. sobre la cuestión relativa al encaje de la motivación como motivo de anulación en los motivos previstos en el artículo 41 LA, S. SÁnchez LoREnzo, "Anulación parcial de laudo en equidad contrario al orden público por falta de motivación: la mal entendida equivalencia jurisdiccional (STC 65/2021, de 15 de marzo)”, La Ley Mediación y Arbitraje, Junio 2021, Núm. 7.
} 
nales nacionales y al Tribunal de Justicia garantizar la plena aplicación del Derecho de la Unión en el conjunto de los Estados miembros y la tutela judicial de los derechos que ese ordenamiento confiere a los justiciables " ${ }^{\prime 18}$. Tan elocuente manifestación - garantizar la plena aplicación del Derecho de la Unión y la tutela judicial del justiciable- se hace, precisamente, en el contexto de una acción de anulación de un laudo arbitral; que no en otro. Así las cosas, cabe plantearse si, por lo menos para supuestos de dimensión europea, la afirmación del TC en cuya virtud "el deber de motivación de los laudos no nace del art. 24 CE, es decir del derecho fundamental a la tutela judicial efectiva, sino del art. 37.4 LA" es compatible con el punto de partida que el TJUE asume, precisamente, en supuestos de anulación de laudos y que sí ve en el control del mismo una garantía a "la tutela judicial de los derechos que ese ordenamiento confiere a los justiciables". Y siendo en la dimensión europea el control del laudo una garantía del justiciable -como expresamente destaca el TJUE-, no veo otra forma de garantizar tal tutela si no es por la vía del control de la motivación.

16. Establecido lo anterior -elocuente de por sí- procede traer a colación los razonamientos que el TJUE desarrolló en la sentencia Eco Swiss; razonamientos alejados del punto de partida que ahora asume el TC. Así, es ya muy sintomático que el TJUE advierta de inicio en este fallo que, de ser aplicable Derecho de la Unión al fondo de la controversia (no necesariamente imperativo), el control del orden público implica un control limitado del Derecho aplicado al fondo del asunto. A partir de aquí, el TJUE demanda un control especial de las normas imperativas del Derecho de la Unión: un control que permita efectivamente apreciar si, en el supuesto de hecho, se han observado -o inobservado- los límites o prohibiciones impuestos por el Derecho imperativo de la UE. Finaliza el TJUE su razonamiento imponiendo a los jueces de los Estados miembros una interpretación específica del artículo V.2.b/ CNY acorde a lo anterior; esto es, exigiendo a los jueces de los Estados miembros la apreciación de la cláusula de orden público en caso de inobservancia de los límites o prohibiciones impuestos por el Derecho imperativo de la UE. El fallo es cristalino a este respecto: "32, En primer lugar, procede señalar que si un arbitraje convencional suscitara cuestiones de Derecho comunitario, los órganos jurisdiccionales ordinarios podrían tener que examinar estas cuestiones, especialmente en el marco del control del laudo arbitral, de mayor o menor entidad según el caso. A partir de aquí, "35. ... las exigencias relativas a la eficacia del procedimiento arbitral justifican que el control de los laudos arbitrales tenga carácter limitado $y$ que sólo pueda obtenerse la anulación de un laudo o la denegación del reconocimiento en casos excepcionales $^{19}$. Ese carácter limitado deviene en un carácter más amplio cuando el Derecho a examinar sea Derecho imperativo: 36. No obstante..., el artículo 85 del Tratado [actual art. 101 TFUE] constituye una disposición fundamental indispensable para el cumplimiento de las misiones confiadas a la Comunidad, especialmente para el funcionamiento del mercado interior. La importancia de dicha disposición hizo que los autores del Tratado establecieran expresamente en el apartado segundo del artículo 85 del Tratado [actual art. 101 TFUE], que los acuerdos y decisiones prohibidos por este artículo son nulos de pleno Derecho. 37. De ello se deduce que, en la medida en que un órgano jurisdiccional nacional deba, en aplicación de sus normas procesales internas, estimar un recurso de anulación de un laudo arbitral basado en la inobservancia de normas nacionales de orden público, también debe estimar tal recurso basado en la inobservancia de la prohibición impuesta en el apartado 1 del artículo 85 del Tratado [actual art. 101 TFUE]". 38. No obsta a esta conclusión el hecho de que el [CNY], ratificado por todos los Estados miembros, establezca que sólo se podrá denegar el reconocimiento y la ejecución de la sentencia arbitral si se prueba la existencia de determinados vicios, en concreto, que la sentencia incumple o excede de los términos de la cláusula compromisoria, que la sentencia no es aún obligatoria para las partes o que el reconocimiento o la ejecución de la sentencia son contrarios al orden público del país en el que se solicita su reconocimiento o la ejecución... 39. En efecto, por los motivos mencionados en

\footnotetext{
18 Citada en nota a pie núm. 4.

19 En la versión alemana de esta sentencia la postura a favor de una revisión limitada del laudo se entiende mucho mejor: "Die Erfordenisse der Effizienz des Schiedsverfahrens rechtfertigen [es], Schiedssprüche nur im beschränktem Umfang zu überprüfen und die Aufhebung eines Schiedspruchs oder die Versagung seiner Anerkennung nur in außergewöhnliche Fällen vorzusehen".
} 
el apartado 36 de la presente sentencia el artículo 85 del Tratado [actual art. 101 TFUE] puede considerarse una disposición de orden público en el sentido de dicho Convenio.

17. Evidentemente, si el TJUE dice que la aplicación de la cláusula de orden público prevista en el CNY debe apreciarse para denegar el execuátur del laudo arbitral en supuestos de inobservancia del Derecho imperativo de la UE, con mayor motivo debe poder accionarse la misma cláusula en sede de anulación. Lo contrario sería tanto como crear un desequilibrio o distinción absurda entre un orden público aplicable en sede de execuátur y un orden público aplicable en sede de anulación.

18. La posterior sentencia Achmea -que dedica un párrafo ad hoc al arbitraje comercial- no solo confirma esta jurisprudencia, sino que, además, recuerda expresamente que el control del laudo arbitral en sede de anulación comprende necesariamente al examen de las normas fundamentales del Derecho de la Unión. Hasta tal punto debe llegar ese examen -y esto bien podría considerarse como una guía sobre el alcance de la revisión de la motivación- que, en su caso, el tribunal de anulación debe incluso poder plantear la correspondiente cuestión prejudicial ante el TJUE sobre la interpretación del derecho aplicable al fondo del arbitraje. Es decir, por más que el TC diga que solo cabe una revisión in procedendo del laudo arbitral, para el TJUE el control in iudicando es incluso obligado en determinados supuestos -muy limitados, pero también muy importantes-: "54. Ciertamente, por lo que se refiere al arbitraje comercial, el Tribunal de Justicia ha declarado que las exigencias relativas a la eficacia del procedimiento arbitral justifican que el control de los laudos arbitrales ejercitado por los órganos jurisdiccionales de los Estados miembros tenga carácter limitado, siempre que las disposiciones fundamentales del Derecho de la Unión puedan ser examinadas en el marco de dicho control y, en su caso, puedan ser objeto de una petición de decisión prejudicial ante el Tribunal de Justicia (véanse, en este sentido, las sentencias de 1 de junio de 1999, Eco Swiss, C-126/97, EU:C:1999:269, apartados 35, 36 y 40, y de 26 de octubre de 2006, Mostaza Claro, C-168/05, EU:C:2006:675, apartados 34 a 39)".

19. Basta con confrontar este párrafo de la sentencia Achmea con las abruptas afirmaciones del TC para constatar que éste último ha impuesto un límite al control del laudo arbitral que la jurisprudencia del TJUE expresa y conscientemente no quiere. Por lo menos para supuestos de arbitraje europeo. De hecho, con una interpretación tan radical como la que el TC impone, el diálogo entre el TJUE y el órgano judicial del Estado miembro encargado del control del laudo es inviable: diálogo que el mismo TJUE plantea como canon de control del laudo. Es decir, el control debe llegar hasta tal punto que el órgano judicial, al examinar el laudo, pueda dialogar con el TJUE sobre las dudas de interpretación del Derecho de la UE. Esta interpretación -de control limitado, pero control- es, además, la única que permite al TJUE preservar el control sobre el Derecho de la UE; que es, en última instancia, de lo que se trata ${ }^{20}$.

20. Por último, cabe también preguntarse si la férrea posición adoptada por el TC en este contexto hubiera sido la misma si el control del laudo se hubiese planteado en un supuesto de corrupción. Tema candente en la jurisprudencia comparada ${ }^{21}$, que bien demuestra la dificultad de encajar las afirmaciones del TC en todos los supuestos de anulación posibles.

\section{La cuestión prejudicial}

21. Dictada la sentencia de amparo, el TSJ dicta nueva sentencia tomando en consideración los criterios que el TC impone ${ }^{22}$. El "segundo fallo" asume, como no podía ser de otro modo, el criterio del

\footnotetext{
${ }^{20}$ Por eso, precisamente, la UE no ratificó el CEDH. El dictamen que su momento emitió el TJUE sobre esta cuestión es particularmente esclarecedor: Dictamen 2/13 del TJUE, 18 diciembre 2014, ECLI:EU:C:2014:2454.

${ }^{21}$ Vid. I. IANCU, "Addressing corruption in international arbitration: a look at the Alstom and Bariven cases", en, C. GonzÁlez- Bueno (Ed.), 40 under 40 International Arbitration (2021), Madrid, Dykinson, 2021, pp. 305-317.

22 STSJ de Madrid, 21 abril 2021, ECLI:ES:TSJM:2021:4401.
} 
TC, si bien se hace lamentable eco de la desafortunada afirmación del TC. Dice también esta sentencia: "En consecuencia, la motivación de los laudos arbitrales carece de incidencia en el orden público".

22. En cualquier caso, este segundo fallo contiene un interesante y extenso voto particular -que, en lo principal, comparto- y que, a diferencia de la sentencia, es sensible a la jerarquía de "los principios de primacía y eficacia directa del Derecho de la Unión, en relación con las Directivas MIFID”. Siendo esto innegablemente así y siendo como eran de aplicación las Directivas MIFID al supuesto -el voto particular de este "segundo fallo" lo explica con mucha claridad-, cabe cuestionarse entonces sobre la oportunidad de una cuestión prejudicial ante el TJUE sobre esta cuestión. A mi juicio, hubiera sido muy interesante tener la opinión del TJUE sobre la compatibilidad de los criterios establecidos por el TC en su sentencia con los criteritos establecidos por el TJUE en sus sentencias Eco Swiss y Achmea -plenamente aplicables al supuesto de autos-. De hecho, estimo que por la dimensión europea del supuesto, la citada cuestión era exigible. Lamentablemente, parece que en autos no se consideró la oportunidad de la misma; pero ello no debería suponer que, a futuro, y en supuestos como los de autos, se considere seriamente esta opción.

\section{Anulación parcial por aplicación de la cláusula de orden público}

23. Aunque finalmente el TC no se haya pronunciado expresamente sobre la procedencia o no de la nulidad parcial del laudo por aplicación de la cláusula de orden público, no puede dejar de hacerse mención a la opinión -que comparto- del Ministerio Fiscal sobre el particular. Como recoge la sentencia objeto de comentario, por aplicación del principio de justicia rogada en materia arbitral y el principio de permanencia de los actos, el Ministerio Fiscal estima que "aquello que haya sido objeto del laudo y no se vea contaminado por ninguna de las causas del art. 41 debe mantener su validez".

24. En efecto, no deja de ser lamentable que el tercer párrafo del artículo 41 LA limite la anulación parcial del laudo arbitral a determinados supuestos. En concreto, la anulación parcial se predica respecto de dos motivos de nulidad: extralimitación de los árbitros (incongruencia extra petita y otras manifestaciones) y arbitrabilidad. Que la anulación parcial abarque a estos supuestos es perfectamente comprensible: puede que solo una parte de la controversia sea inarbitrable y puede también que la incongruencia o extralimitación se manifieste también de forma limitada ${ }^{23}$. Sin embargo, la invalidez del convenio arbitral, la vulneración de los derechos de defensa o las irregularidades procedimentales (art. $41.1 \mathrm{a} /, \mathrm{b} / \mathrm{y} \mathrm{d} /$, respectivamente) constituyen motivos de anulación que invalidan automáticamente el laudo en su integridad; no son motivos de anulación, por tanto, que puedan considerarse de forma matizada de cara a una anulación parcial. Y así, por ejemplo, si el convenio arbitral es inválido, es evidente que ninguna parte del laudo puede "salvarse".

25. Ahora bien, no ocurre lo mismo con el orden público como motivo de anulación. En efecto, aunque el precepto no lo contemple, es innegable que la apreciación del orden público como motivo de anulación también puede ser parcial: los árbitros pueden vulnerar el orden público de distintas formas en un aspecto, cuestión o pronunciamiento concreto de la controversia, de tal forma que en el laudo pueda delimitarse el concreto ámbito de tal vulneración. Siendo esto así, y teniendo en cuenta que el artículo 41.3 LA no recoge el orden público como motivo de anulación de apreciación parcial, se impone una interpretación teleológica del precepto basada en su auténtica ratio: la conservación, en la medida de lo posible, del laudo ${ }^{24}$. En consecuencia, debe admitirse la nulidad parcial del laudo por aplicación del orden público a un aspecto, cuestión o pronunciamiento concreto del laudo. De hecho, los tribunales

${ }_{23}$ Para un ejemplo de anulación parcial por aplicación del artículo 41.1.c/, STSJ del País Vasco 13 diciembre 2019, ECLI:ES:TSJPV:2019:3811.

${ }^{24}$ Ya en este sentido, J. Cadarso Palau, “Artículo 41”, en J. González Soria (Coor.), Comentarios a la nueva Ley de Arbitraje, Aranzadi, Cizur Menor, 2011, p. 593. 
aceptan con carácter general esta interpretación y, en consecuencia, han venido anulando parcialmente laudos arbitrales en aplicación de la excepción de orden público ${ }^{25}$. Único requisito en este contexto es que las cuestiones objeto de nulidad "tengan sustantividad propia y no parezcan indisolublemente unidos a la cuestión principal"26. Y así, por ejemplo, se ha procedido a anular únicamente la parte del laudo relativa a las costas, por imponerse sin motivación "que supere el canon de arbitrariedad o se acomode a las reglas de la lógica" 27 ; la parte relativa a los intereses fijados en el laudo ${ }^{28}$; algún pronunciamiento concreto del laudo por infracción de las reglas de la carga de la prueba ${ }^{29}$; así como cuando no hayan sido aplicadas normas imperativas a un pronunciamiento concreto del laudo ${ }^{30}$.

26. En cualquier caso, mientras no se produzca una necesaria modificación de la Ley de Arbitraje en este punto, la aportación del Ministerio Fiscal del TC supone un elemento relevante más a favor de admitir la anulación parcial del laudo arbitral en aplicación de la cláusula de orden público.

\section{A modo de conclusión}

27. A modo de conclusión, de lo hasta aquí dicho pueden extractarse las siguientes ideas:

- Determinadas afirmaciones del TC hechas en la sentencia de referencia -"la motivación de los laudos arbitrales carece de incidencia en el orden público"- deben ser necesariamente matizadas, atendiendo si al fondo del asunto le son o no de aplicación normas imperativas del Derecho de la UE. Del mismo modo que el TC ha matizado en esta sentencia el alcance de su desafortunada expresión - arbitraje como equivalente jurisdiccional- es muy necesario ahora delimitar el alcance de expresiones tan contundentes como las citadas más arriba.

- Por otro lado, para asegurar una mínima coherencia con la jurisprudencia europea (particularmente, sentencias Eco Swiss y Achmea), además de imponerse una interpretación amplia de lo que el TC califica como "errores in procedendo", debe entenderse también que en supuestos de aplicación de Derecho imperativo hay un limitado juego del orden público material.

- Por fin, tan severa es la desconexión del TC con la jurisprudencia del TJUE que cabe incluso preguntarse si el mismo Tribunal ha vulnerado el derecho del justiciable a un proceso con todas las garantías (art. 24.2 CE), en la medida en que no ha resuelto conforme al sistema de fuentes establecido ${ }^{31}$ : al supuesto le eran de aplicación los criterios que el TJUE ha establecido reiteradamente en su jurisprudencia y, sin embargo, no han sido aplicados.

\footnotetext{
${ }^{25}$ STSJ de Madrid, 2.2.2016, ECLI:ES:TSJM:2016:702; STSJ de Madrid, 11 octubre 2016, ECLI:ES:TSJM:2016:10733; STSJ de Madrid, 13 diciembre 2018, ECLI:ES:TSJM:2018:12822; STSJ de Madrid, 1 octubre 2019, ECLI:ES:TSJM:2019:9201.

26 Paradigmática, SAP de Sevilla, 20 diciembre 1996, RCEA, 1998, pp. 111-114.

27 STSJ de Madrid, 11 octubre 2016, ECLI:ES:TSJM:2016:10733. En sentido similar, STSJ de Madrid, 21 enero 2019 , ECLI:ES:TSJM:2019:971.

${ }^{28}$ STSJ de Andalucía, 12 enero 2015, ECLI:ES:TSJAND:2015:826.

29 STSJ de Madrid, 12 febrero 2019, ECLI:ES.TSJM:2019:978.

30 STSJ de Madrid, 13 diciembre 2018, ECLI:ES:TSJM:2018:12822.

31 STC 37/2019, de 26 de marzo, ECLI:ES:TC:2019:37.
} 